\title{
Increasing the vitamin D level of oyster mushrooms by UV light
}

\author{
Győrfi, J., Kovács, A. \& Szabó A. \\ Corvinus University Budapest - Faculty of Horticultural Science, Department of Vegetable and Mushroom \\ Growing(gomba@uni-corvinus.hu)
}

\begin{abstract}
Summary: Vitamin D is essential for the human body and mushrooms are one of the natural sources of it. Many research works are aimed at enhancing the vitamin $\mathrm{D}_{2}$ content of mushrooms with UV irradiation in order to increase their vitamin $\mathrm{D}_{2}$ level, by transforming their natural ergosterol content into vitamin $\mathrm{D}_{2}$. The subjects of most of these studies are different kind of post-harvest cultivated mushrooms. In our experiment biologically active, pre-harvest oyster mushrooms were treated in the growing room with UVB and UVC light. UVB and UVC lamps (operating on 312 and $254 \mathrm{~nm}$ ) and 6 time periods of irradiation (15, 30, 45, 60, 75 and $90 \mathrm{~min}$ ) were used. After three consecutive days of treatments the yield were measured and samples were taken for vitamin $\mathrm{D}_{2}$ and ergosterol analysis. Data showed considerable increase (from $0,67 \mu \mathrm{g} / \mathrm{g}$ to $3,68 \mu \mathrm{g} / \mathrm{g}$, f.w.) in vitamin $\mathrm{D}_{2}$ levels at every time period in case of both wavelengths.
\end{abstract}

Key words: Oyster mushroom, UVB and UVC light, ergosterol, vitamin D

\section{Introduction}

The dietetic value of the different mushroom species is well known and their role in treating and preventing various illnesses is getting more important as well. Many people nowadays suffer from so-called "civilization diseases", such as heart and cardiovascular diseases and cancers. The elements and metabolites of mushrooms enable them to play a vital role in treating these serious illnesses (Szili, 2008).

Oyster mushroom species belong to the group of healthy foods, as they contain high levels of protein and vitamins, but low level of energy. Lelley and Vetter (2005) examined the nutritional composition of cultivated mushroom species, including Pleurotus ostreatus, and found that the oyster mushroom can play a vital role of preserving good health. Due to the low energy and glucose level, this species is especially suitable for those consumers who suffer from high blood pressure. Oyster mushrooms are rich in vitamins B and $\mathrm{D}$, and minerals, such as potassium and phosphorus.

Chang (2008) found that one of the most important nutritional values of Pleurotus ostreatus is the protein content, which - depending on the cultivar - can be 10-30 or even $40 \%$ of the dry matter. It is notable, that oyster mushrooms contain all of the essential amino acids. Their lipid level is different in the cap and in the stipe, but the total amount is around 3-5\% (dry matter). Although the carbohydrate content of the Pleurotus species varies between $3-28 \%$ (d.m.), and a certain amount of raw fiber can be measured as well, Pleurotus ostreatus have higher levels of carbohydrate (57\%) and raw fiber (14\%), $47 \%$ of which is dietary fiber.
Due to Chang (2008), the caps of oyster mushrooms contain a number of medicinal substances. In almost every fruiting body, there are polysaccharides, with the ability to regulate antitumor activity. Besides these polysaccharides, which are 1-3 B D glucans, oyster mushrooms have other glucans. Although these glucans do not change the working of the immune system, they boost the activity of the natural killer cells and the lymphokines. Pleurotus species are proven to have antitumor effects, by blocking tumor growth. They can be used against inflammations; they are able to lower blood pressure and lipid concentration in the plasma (Chang, 2008). Researches proved that oyster mushrooms boost antioxidant activity. In these studies, the antioxidant activity was measured in different fractions (acidic, phenolic, alkaline and neutral), of which the activity measured in the phenolic fraction was the highest (Chang, 2008).

It is recognized for more than one century that vitamin D is essential for the proper functioning of a healthy human body. Vitamin D has is necessary for bone mineralization by promoting calcium and phosphorous absorption in the small intestine and secretion in the kidneys. Vitamin D affects cell growth and the efficiency of the immune system (Grant \& Holick, 2005; Holick, 2008). An adequate vitamin D level is essential of preventing a number of illnesses, which affect the whole population of the world. These diseases, such as rickets, osteoporosis, heart disease, obesity and diabetes, affect people of all ages and living in different parts of the globe (Holick, 2006). Recent studies aimed at trying to find ways of using vitamin $\mathrm{D}$ in cancer prevention and treatment (Mehta \& Mehta, 2002; Bouillon et al., 2006; Garland et al., 2006). 
The goal of numerous recent surveys is to estimate the prevalence of inadequacy of vitamin D in the world's population (Chapuy et al., 1997; Overesen et al., 2003; Gordon et al., 2004; Calvo \& Whiting, 2006; Rodríguez et al., 2008; Vives \& Moreiras Tuny, 2008; Looker et al., 2011). Due to data, vitamin D deficiency is a global phenomenon, it effects most of the population, thus it has been recognized as a pandemic (Holick \& Chen, 2008).

Although the diseases deriving from vitamin D deficiency are common, there are certain groups of the population who are more at risk of not having an adequate level of vitamin D. As one type of vitamin D is formed in the human skin by UV light, it is most likely that the vitamin D level of the human body will drop during winter (when the UV radiation is lover) (Tylavsky et al., 2006). Studies proved that the prevalence of vitamin D deficiency is more common in case of those people who live in high latitudes.

People with dark skin are also at higher risk, as their skin contains melanin, which blocks UV light passing through the upper layers of the skin. Not only the color but the age of the skin is important as well. In older age, the skin's vitamin D synthesizing ability is lower (Jasinghe \& Perera, 2006; Borradale \& Kimlin, 2008).

In order to prevent rickets in children and osteoporosis and osteomalacia in adults, it is necessary to consume foods with high level of vitamin D (Mau et al., 1998; Holick \& Chen, 2008).

As vitamin D deficiency affects high proportion of the population, and recognizing that proper amount of vitamin $\mathrm{D}$ is necessary to prevent many diseases and malformations, experts started to find ways of producing synthetic vitamin D. The outcome of these studies is that nowadays supplementary vitamin D is available in various form (e.g. drops or pills). Besides these products, fortified foodstuffs, such as milk products and juices are also available for consumers, because certain groups prefer getting vitamin D from a natural source, and not from supplements. (Calvo \& Whiting, 2006; Grant \& Holick, 2005). These products can be found almost exclusively in the USA, and they contain synthetic vitamin D.

Vitamin D exists in various forms, which have similar biological effects. They are all optically active, colorless, liposoluble and they remain active even on $100 \mathrm{C}^{\circ}$ (Gasztonyi, 1979). Cholecalciferol (vitamin $\mathrm{D}_{3}$ ) is produced in the human skin by sunlight (Overesen et al., 2003; Shrapnel \& Truswell, 2006), while Ergocalciferol (vitamin $\mathrm{D}_{2}$ ) can be obtained from a few natural food sources, from fortified foodstuff and from supplements. The provitamins of vitamins D are ergosterol (in plants) and 7-dehydrocholesterol (in animals) (Gasztonyi, 1979).

In the group of sterols found in mushrooms, ergosterol is the most important, as it is the provitamin of vitamin D2. When exposed to UV light, ergosterol undergoes photolysis and form vitamin $\mathrm{D}_{2}$ and other photoirradiation products (lumisterol and tachysterol). The provitamin of vitamin D3 is 7-dehydrocholesterol. This endogenous provitamin (along with cholesterol) is present in the fat tissue under the animal and human skin. It is found mostly in the liver oil of sea fish (Nádor, 1982).

The two types of vitamin D are together responsible for providing the adequate vitamin $\mathrm{D}$ intake for a human body, thus it is necessary to consume foods rich in vitamin D (Mau et al., 1998; Oversen et al., 2003; Shrapnel \& Trusvwell, 2006).

The number of foodstuff with high vitamin D levels is limited. These products are e.g. meat, fish (especially fish liver oil) and milk products. By consuming these products, humans can cover 6-80\% of their necessary daily vitamin D intake (U.S.D.A., Agricultural Research Service, 2009). Since no plant-products (fruit or vegetables) consists any vitamin $\mathrm{D}$, vegetarians, who are not consuming even milk products, are at risk of vitamin D deficiency (LambergAllardt, 1993; Mattila et al., 2000; Jasinghe \& Perera, 2005).

Most mushroom species contain different levels of ergosterol and vitamin D2. With their high nutritional value and low energy level, mushrooms are considered to be health beneficial foods. They have an especially important role in the nourishment of vegetarians, not only because, mushrooms contain high amount of protein, but because of their vitamin D2 content as well (Mattila et al., 1994; Mattila et al., 2002).

Wild grown mushrooms have higher vitamin D2 level, than the cultivated ones. One serving of wild grown mushrooms (80-90 g) can cover $90-500 \%$ of the requested daily value of vitamin D (U.S. D.A., Agricultural Research Service, 2009). The reason for the higher amount of vitamin $\mathrm{D}_{2}$ present in wild grown mushrooms derives from the fact that most cultivated mushrooms - although they are grown in rooms with natural light-, do not get direct UV radiation. Some species (like Agaricus bisporus) are grown in almost complete dark, where the absence of UV radiation results a lower level of vitamin $\mathrm{D}_{2}$. Although they consist less vitamin $\mathrm{D}_{2}$, cultivated mushrooms contain more ergosterol than wild grown mushroom species (Teichmann et al., 2007; Jasinghe et al., 2007).

Since the distribution of vitamin D2 in the tissues is uneven. It proven, that the caps contain more vitamin D than the stipes, where the concentration is the lowest. Vitamin D is present in the highest amount close to the surface of the cap, that is why the mushrooms should not be pealed before cooking (Györfi et al., 2010).

Number of experiments and studies proved that ergosterol content of post-harvest mushrooms can be converted into vitamin $\mathrm{D}_{2}$ by artificial UV irradiation. In these tests different irradiation times and wavelengths were used. It is confirmed, that vitamin $\mathrm{D}_{2}$ concentration in cultivated mushroom can be enhanced up to nine folds by applying different UV irradiation methods (Jasinghe \& Perera, 2005; Mau et al., 1998).

At the time there is no sufficient reference or published data which would indicate how ergosterol and vitamin $\mathrm{D}_{2}$ concentration would change in cultivated mushroom, if they would be treated with UV radiation not post-harvest, but before picking, still during their growing period. In our study the aim was to irradiate mushrooms with UV light during cultivation, in pre-harvest stage, while they are still biologically active and still growing. 


\section{Materials and methods}

In this study the 'HK35' strain of oyster mushroom was used. Different wavelengths of UV radiation were applied in different time periods to study the effect of UV light and duration of irradiation on changes in vitamin $\mathrm{D}_{2}$ level. Two types of UV lamps (operating on $312 \mathrm{~nm}$ - in the ' $\mathrm{B}$ ' range and $254 \mathrm{~nm}$ - in the ' $\mathrm{C}$ ' range of UV light) were used.

Besides measuring the changes in vitamin D2 content due the different UV treatments, the ergosterol levels were registered as well. One of the purposes of the experiment was to detect any correlation between vitamin D2 and ergosterol levels.

The experiment was set up in the test chamber of the Corvinus University of Budapest, Faculty of Horticultural Science, Department of Vegetable and Mushroom Growing.

For the experiment, $260 \mathrm{~kg}$ oyster mushroom substrate was provided by the Pilze-Nagy Ltd. (Kecskemét, Hungary).

The substrate was inoculated with 'HK 35' spawn. 26 bags were filled with $10 \mathrm{~kg}$ substrate, respectively. 12 of the 26 were used for UVB, 12 for UVC treatments and 2 were untreated control. Picture $\mathrm{x}$. and $\mathrm{x}$. shows the setting up of the experiment.

After placing the bags on the shelves of the growing chamber, each bag was perforated in 8 places.

The Vilbert Lourmat-115M type UVB and UVC lamps were set up above the bags, approx. $32 \mathrm{~cm}$ from the surface of the fruiting bodies.

During the entire growing period, in every development stage of the mushroom cultivars, the ambient conditions were registered.

Six different irradiation time periods $(5,10,15,20,25$ and 30 minutes) were applied in 3 repeats (one treatment per day, 24 hours apart, for three consecutive days), this way in the end, the treated surfaces got 15 to 90 minutes irradiation.

The treatments of oyster mushroom were carried out in 2 repeats ( 2 bags with total $20 \mathrm{~kg}$ compost). The UV irradiation went on from 4 days after the primordia appeared.

Table 1 shows the names of treatments and repeats.

Table 1. The names of treatments and repeats used in the experiment

\begin{tabular}{|c|c|c|c|c|c|c|c|}
\hline \multirow{2}{*}{ Wavelengths } & \multicolumn{7}{|c|}{ Irradiation time (min) } \\
\cline { 2 - 9 } & $\mathbf{0}$ & $\mathbf{1 5}$ & $\mathbf{3 0}$ & $\mathbf{4 5}$ & $\mathbf{6 0}$ & $\mathbf{7 5}$ & $\mathbf{9 0}$ \\
\hline UVB & control & B15 & B30 & B45 & B60 & B75 & B90 \\
\hline UVC & control & C15 & C30 & C45 & C60 & C75 & C90 \\
\hline
\end{tabular}

For analysis 13 x $500 \mathrm{~g}$ sample were taken from each treatment.

The determination of vitamin $\mathrm{D}_{2}$ and ergosterol concentration were carried out in the Corvinus University of Budapest, Faculty of Food Science, Department of Applied Chemistry, by Abrankó László, PhD and Attila Gyepes.

\section{Results and discussion}

The changes of vitamin D level after UVB treatments are shown on Fig. 1. The values are given in $\mu \mathrm{g} / \mathrm{g}$ fresh weight.

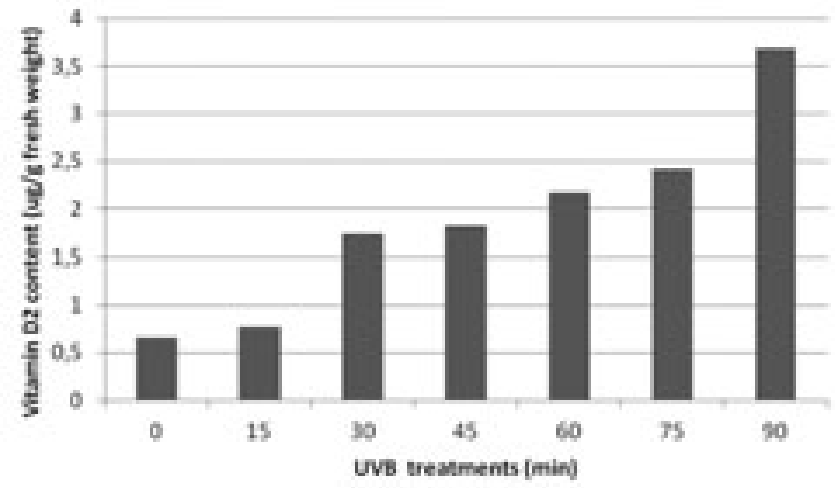

Fig. 1. Changes in vitamin $D_{2}$ content in oyster mushrooms after 0 to 90 minutes of UVB treatments

UVB treatments caused a substantial change in vitamin $\mathrm{D}_{2}$ level of the biologically active oyster mushrooms. The vitamin $\mathrm{D}_{2}$ concentration of the treated mushrooms grew by 14-450\% compared to the untreated control. The shortest irradiation time $(15 \mathrm{~min})$ resulted the lowest growth, the vitamin $\mathrm{D}_{2}$ level got only $14 \%$ higher than that in the control (from $0,67 \mu \mathrm{g} / \mathrm{g}$ to $0,76 \mu \mathrm{g} / \mathrm{g}$ ). The 90 minutes treatment proved to be the most efficient, as it caused a $450 \%$ growth in vitamin $\mathrm{D}_{2}$ level (from $0,67 \mu \mathrm{g} / \mathrm{g}$ to $3,68 \mu \mathrm{g} / \mathrm{g}$ ).

As the results of UVC treatments are show on Fig. 2., UVC light proved to be less effective in increasing the vitamin $\mathrm{D}_{2}$ level of oyster mushrooms.

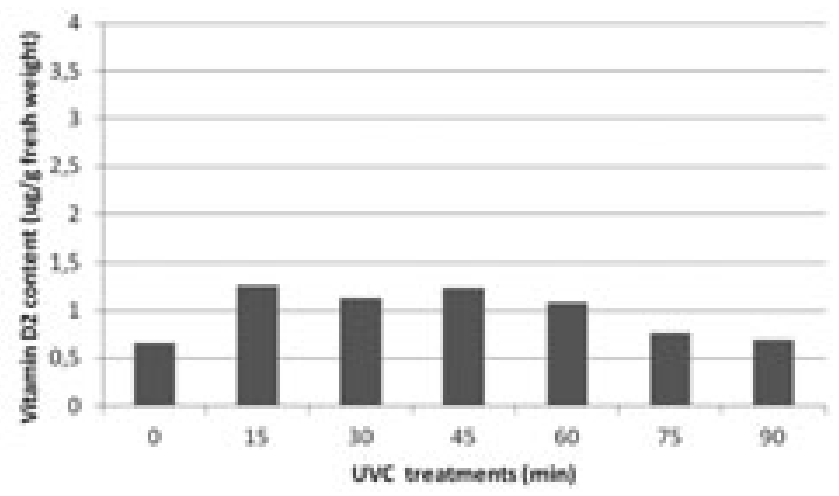

Fig. 2. Changes in vitamin $\mathrm{D}_{2}$ content in oyster mushrooms after 0 to 90 minutes of UVC treatments

The lowest growth was registered in case of the 90 minutes treatment, where the vitamin $\mathrm{D}_{2}$ level changed from $0,67 \mu \mathrm{g} / \mathrm{g}$ to $0,7 \mu \mathrm{g} / \mathrm{g}$, which is only an approximately $5 \%$ change compared to the control sample. The shortest UVC treatment proved to be the most effective, as it caused a $89 \%$ growth in vitamin $\mathrm{D}_{2}$ content (from $0,67 \mu \mathrm{g} / \mathrm{g}$ to $1,26 \mu \mathrm{g} / \mathrm{g}$ ).

Due to data it is seen that the efficiency of UVC light is lower than that of the UVB light.

The changes of ergosterol concentration are shown on Fig. 3. and 4. The values are given in $\mu \mathrm{g} / \mathrm{g}$ fresh weight.

As Fig. X. shows, although UV light caused the ergosterol content to decrease, this change is not steady. After UVB treatments, a $28-77 \%$ lower ergosterol level was measured. 


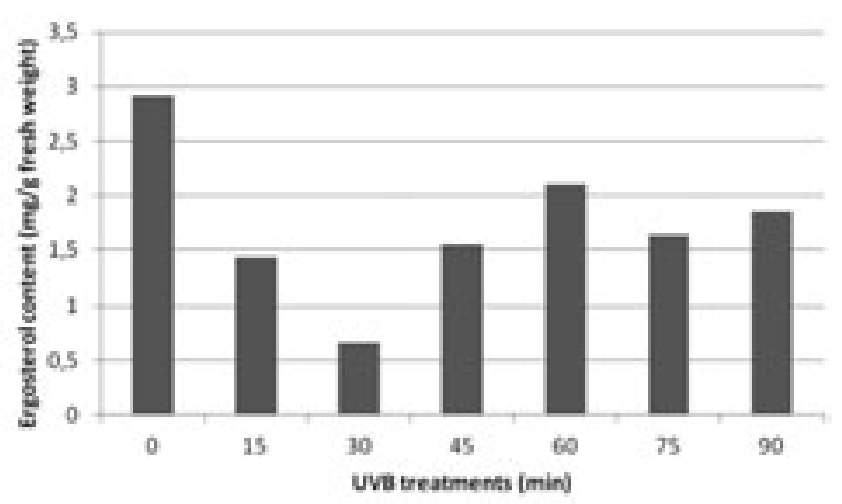

Fig. 3. Changes in ergosterol content in oyster mushrooms after 0 to 90 minutes of UVB treatments

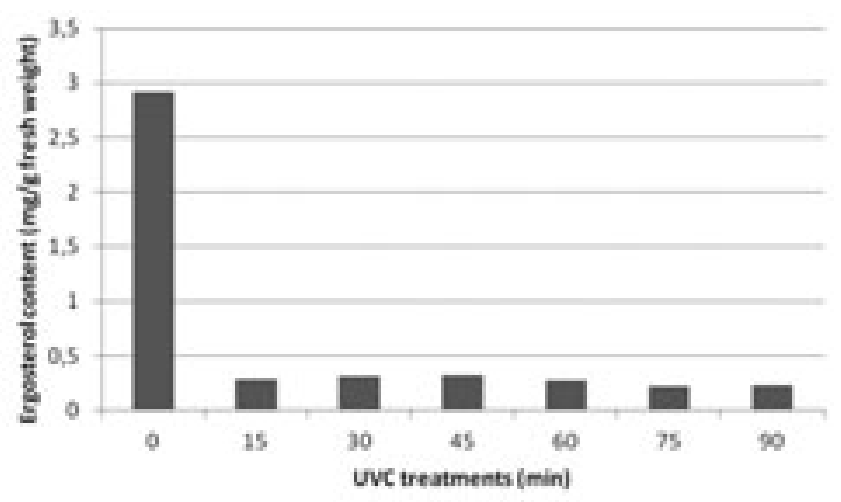

Fig. 4. Changes in ergosterol content in oyster mushrooms after 0 to 90 minutes of UVC treatments

UVC irradiation caused the ergosterol concentration to drop by 88,7-92,6\% (from 2,92 mg/g to 0,22 mg/g) (Fig. x.). There are no substantial differences between the results of each of the treatments, as the ergosterol content of the treated samples varies between 0,22 and $0,33 \mathrm{mg} / \mathrm{g}$.

Due to data, no correspondence of the vitamin $\mathrm{D}_{2}$ and ergosterol level can be seen.
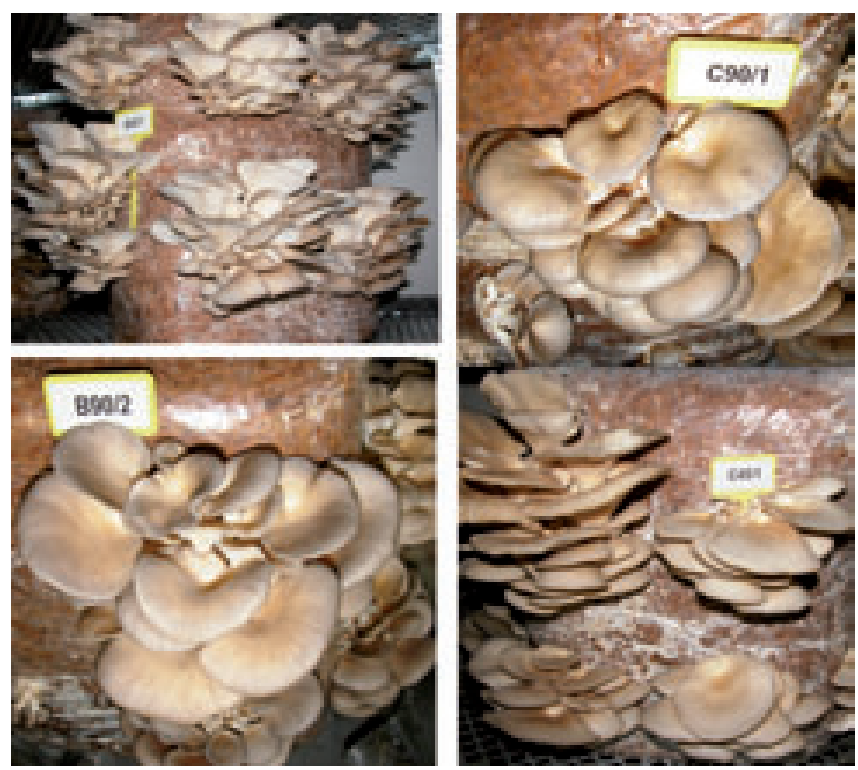

\section{References}

Borradale, D. \& Kimlin, M. (2009): Vitamin D in health and disease: an insight into traditional functions and new roles for the 'sunshine vitamin'. Nutr. Res. Rev., 22: 118-136.

Bouillon, R., Eelen, G., Verlinden, L., Mathieu, C., Carmeliet, G. \& Verstuyf, A. (2006): Vitamin D and cancer. J. Steroid Biochem. 102: 156-162.

Calvo, M.S. \& Whiting, S.J. (2006): Public health strategies to overcome barriers to optimal vitamin D status in populations with special needs. J. Nutr., 4: 1135-1139.

Chang, S. T. (2008): Training manual on mushroom cultivation technology. - United Nations - Nations Unies, Economic and Social Commission for Asia and the Pacific, Asian and Pacific Centre for Agricultural Engineering and Machinery, Beijing, China. Chapuy, M.-C., Preziosi, P., Maamer, M., Arnaud, S., Galan, P., Hercberg, S. \& Meunier, P.J. (1997): Prevalence of vitamin D insufficiency in an adult normal population. Osteoporosis Int., 7: 439-443.

Garland, C.F., Garland, F.C., Gorham, E.D., Lipkin, M., Newmark, H., Mohr, S.B. \& Holick, M.F. (2006): The role of vitamin $\mathrm{D}$ in cancer prevention. American Journal of Publick Health, 96, (2): 252-261.

Grant, W. B. \& Holick, M.F. (2005): Benefits and requirements of Vitamin D for optimal Health: a review. Altern. Med. Rev. 2: 94-111.

Gasztonyi, K. (1979): Az élelmiszerkémia alapjai, Mezőgazdasági Kiadó, Budapest, 197-199.

Gordon, C.M., DePeter, K.C., Feldman, H.A., Grace, E. \& Emans, S.J. (2004): Prevalence of vitamin D deficiency among healthy adolescents. Arch. Pediat. Adol. Med., (158): 532-537.

Győrfi J. 2010. Gombafajok termesztése a világon, Európában és Magyarországon, 8In: GYŐRFI J. (szerk.): Gombabiológia gombatermesztés] p: 114-121.

Holick, M.F. (2006): The role of vitamin D in cancer prevention. Am. J. Publick Health, 2: 252-261.

Holick, M. F. \& Chen, T.C. (2008): Vitamin D deficiency: a worldwide problem with health consequences. Am. J. Clin. Nutr., 4: 1080-6.

Holick, M.F. (2008): Vitamin D: a D-Lightful health perspective. Nutr Rev., 66 (10 Suppl 2), 182-194.

Institute of Medicine, Food and Nutrition Board. Dietary Reference Intakes for Calcium and Vitamin D (2010): Washington, DC: National Academy Press.

Jasinghe, V.J. \& Perera, C.O. (2005): Distribution of ergosterol in different tissues of mushrooms and its effect on the conversion of ergosterol to vitamin $\mathrm{D}_{2}$ by UV irradiation. Food Chemistry. (92): 541-546.

Jasinghe, V.J. \& Perera, C.O. (2006): Ultraviolet irradiation: The generator of vitamin $\mathrm{D}_{2}$ in edible mushrooms. Food Chem., 95: 638-643.

Jasinghe, V.J., Perera, C.O. \& Sablani, S.S. (2007): Kinetics of the conversion of ergosterol in edible mushrooms. J. Food Eng., 79: 864-869.

Lamberg-Allardt, C., Karkkainen, M., Seppanen, R. \& Bistrom, H. (1993): Low serum 25-hydroxyvitamin D concentrations and secondary hyperparathyroidism in middle-aged white strict vegetarians. Am. J. Clin. Nutr., 58: 684-689.

Lelley, J. \& Vetter, J. (2005): The possible role of mushrooms in maintaining good health and preventing diseases. The Spawn run, 5 (3): 4-10.

Looker, A. C., Johnson, C.L., Lacher, D.A., Pfeiffer, C.M., Schleicher, R.L. \& Sempos, C.T. (2011): Vitamin D Status: United States, 2001-2006. NCHS Data Brief, Number 59. 
Mattila, P.H., Piironen, V.I., Uusi-Rauva, E.J. \& Koivistoinen, P.E. (1994): Vitamin D contents in edible mushrooms. J. Agr. Food Chem., 42: 2449-2453.

Mattila, P.H., Suonpää, K. \& Piironen, V. (2000): Functional properties of edible mushrooms. Nutrition, 16: 694-696.

Mattila, P.H., Lampi, A.-M., Ronkainen, R., Toivo, J. \& Piironen, V. (2002): Sterol and vitamin $\mathrm{D}_{2}$ contents in some wild and cultivated mushrooms. Food Chem. 76: 293-298.

Mau, J.L., Chen, P.R. \& Yang, J.H. (1998): Ultraviolet irradiation increased vitamin $\mathrm{D}_{2}$ content in edible mushrooms. J. Agr. Food Chem., 46: 5269-5272.

Mehta, R.G. \& Mehta, R.R. (2002): Vitamin D and cancer. J. Nutr. Biochem., 13: 252-264.

Nádor, K. (1982): Szerves kémia, 25.3: Szterinek, Mezőgazdasági Kiadó, Budapest, p: 508-509.

Ovesen, L, Andersen, R. \& Jakobsen, J. (2003): Geographical differences in vitamin D status, with particular reference to European countries. Proc. Nutr. Soc., 4: 813-21.
Rodríguez Sangrador, M., Beltrán de Miguel, B., QuintanillaMurillas, L., Cuadrado Vives, C. \& Moreiras Tuny, O. (2008): The contribution of diet and sun exposure to the nutritional status of vitamin D in elderly Spanish women: the five countries study (OPTIFORD Project). Nutr. Hosp., 6: 567-76.

Shrapnel, W. \& Truswell, S. (2006): Vitamin D deficiency in Australia and New Zealand: What are the dietary options? Nutrition \& Dietetics, 4: 206-212.

Szili, I. (2008): Gombatermesztők könyve, Mezőgazda Kiadó, Budapest.

Teichmann, A., Dutta, P.C., Staffas, A. \& Jägerstad, M. (2007): Sterol and vitamin $\mathrm{D}_{2}$ concentrations in cultivated and wild grown mushrooms: Effects of UV irradiation. LWT, 40: 815-822.

Tylavsky, F.A, Cheng, S., Lyytikäinen, A., Viljakainen, H. \& Lamberg-Allardt, C. (2006): Strategies to improve vitamin D status in northern European children: exploring the merits of vitamin D fortification and supplementation. J. Nutr., 4, 1130-1134.

U.S. Department of Agriculture, Agricultural Research Service (2009): USDA Nutrient Database for Standard Reference, Release 22. 